\title{
Suppressive effects of an ethanol extract of Gleditsia sinensis thorns on human SNU-5 gastric cancer cells
}

\author{
SE-JUNG LEE ${ }^{1,5^{*}}$, DONG HEE RYU ${ }^{2 *}$, LEE CHAN JANG ${ }^{2}$, SEOK-CHEOL CHO ${ }^{3}$, \\ WUN-JAE KIM ${ }^{4}$ and SUNG-KWON MOON ${ }^{1,5}$
}

\begin{abstract}
${ }^{1}$ Department of Biotechnology, Chungju National University, Chungju, Chungbuk 380-702; ${ }^{2}$ Department of Surgery, Chungbuk National University College of Medicine, Cheongju, Chungbuk 361-763; ${ }^{3}$ Department of Food and Nutrition, Seowon University, Cheongju 361-742; ${ }^{4}$ Department of Urology, Chungbuk National University College of Medicine, Cheongju, Chungbuk 361-763; ${ }^{5}$ School of Food Science and Technology, Chung-Ang University, Ansung 456-756, Republic of Korea
\end{abstract}

Received September 28, 2012; Accepted December 14, 2012

DOI: 10.3892/or.2013.2271

\begin{abstract}
The thorns of Gleditsia sinensis are a traditional Oriental medicine used for the treatment of swelling, suppuration, carbuncle and skin diseases. In the present study, we identified a novel molecular mechanism by which an ethanol extract of Gleditsia sinensis thorns (EEGS) inhibits the growth of the SNU-5 human gastric cancer cell line. EEGS treatment inhibited cell growth and was associated with G1 phase cell cycle arrest at a concentration of $400 \mu \mathrm{g} / \mathrm{ml}\left(\mathrm{IC}_{50}\right)$ in SNU-5 cells. Treatment with EEGS also stimulated p21WAF1 expression, which significantly decreased the expression of cyclins and cyclin-dependent kinases (CDKs). Further study suggested that p38 MAP kinase pathways may be involved in the inhibition of cell proliferation through p21WAF1-dependent G1 phase cell cycle arrest in EEGS-treated cells. In addition, NF- $\mathrm{KB}$ and AP-1 transcription factor binding sites were identified as the $c i s$-elements for tumor necrosis factor- $\alpha$ (TNF- $\alpha$ )-induced matrix metalloproteinase-9 (MMP-9) expression in SNU-5 cells, as determined by gel-shift assay. Treatment of cells with EEGS suppressed MMP-9 expression induced by TNF- $\alpha$ via a decrease in the binding activity of both NF- $\mathrm{KB}$ and AP-1 motifs. These data demonstrate that EEGS-mediated inhibition of cell growth appears to involve the activation of p38 MAP kinase, subsequently leading to the induction of p21WAF1 and the downregulation of cyclin D1/CDK4 and cyclin E/CDK2 complexes. Moreover, EEGS strongly inhibited TNF- $\alpha$-induced MMP-9 expression by impeding the DNA binding activity of NF- $\mathrm{KB}$ and AP-1.
\end{abstract}

Correspondence to: Dr Sung-Kwon Moon, School of Food Science and Technology, Chung-Ang University, Ansung 456-756, Republic of Korea

E-mail: sumoon66@dreamwiz.com

"Contributed equally

Key words: Gleditsia sinensis thorns, gastric cancer, p38 MAP kinase, G1 phase cell cycle arrest, p21WAF1, MMP-9, NF-кB, AP-1
Overall, these results provide a potential mechanism for EEGS in the treatment of gastric cancer.

\section{Introduction}

Gastric cancer, a malignant epithelial tumor, is one of the most common cancers and is the second most common cause of cancer-related mortality in the world $(1,2)$. Recently employed therapies for gastric cancer during the past few years have included chemotherapy, surgery and radiation (3-5). It is generally accepted that systemic chemotherapy is the main option. Although these therapies have led to considerable improvements in gastric cancer treatment, the occurrence of drug resistance, which is associated with poor prognosis, remains a dire issue $(6,7)$. Thus, there is a pressing need for the development of effective drugs for the treatment of gastric cancer.

The regulation of the cell cycle is a series of events leading to the maintenance of cell proliferation in multicellular organisms. Regulation consists of four distinct sequential phases: the G1 phase, the $\mathrm{S}$ phase (synthesis), the G2 phase, and the M phase (mitosis) (8). The major factors involved in this process are cyclins and cyclin-dependent kinases (CDKs), which regulate the progression of the cell cycle (8-10). Progression from the $G_{1}$ to the $S$ phase of the cell cycle predominantly requires the activation of cyclin D1-CDK4 and cyclin E-CDK2 (8). The kinase activity of these cyclins/CDK complexes can be blocked by CDK-inhibitory proteins, including p21WAF1 and p27KIP, which subsequently obstruct G1 cell cycle progression (11). In addition, previous results have suggested that activation of the mitogen-activated protein kinase (MAPK) signaling transduction pathway, such as extracellular signaling-regulated kinase 1/2 (ERK1/2), c-Jun N-terminal kinase (JNK) and p38 MAPK are known to be involved in the inhibition of cell growth (12-14). Accumulative evidence has shown that the p38MAPK signaling transduction pathway may be associated with the process of cell cycle arrest $(13,14)$.

Many studies have found that MMPs, particularly MMP-2 (gelatinase A, 72-kDa gelatinase) and MMP-9 (gelatinase B, 92-kDa gelatinase), promote the degradation of the extracellular matrix (ECM), which is a process that is involved in 
tumor invasion and metastasis $(15,16)$. Previous studies have shown that higher levels of MMP-9 are associated with metastatic tumors such as gastric cancer (17-19). Previous reports have indicated that TNF- $\alpha$ induces MMP-9 expression in cancer cells (20-23). The expression of MMP-9 by TNF- $\alpha$ is mediated via activation of the transcription factors $N F-\kappa B$ and AP-1 in several tumor cell types (20-23).

Gleditsia sinensis has been used mainly in Oriental countries for years as a traditional medicine for the treatment of swelling, suppuration, carbuncle and skin diseases (24). The main constituents of Gleditsia sinensis include stigmasterol, ellagic acid glycoside and lupine acid (25-27). Gleditsia sinensis exhibits a number of biological activities, including the promotion of anti-allergenic, anti-inflammatory and antitumor effects $(29,30)$. Although noticeable progress has been made toward our understanding of the mechanisms of the Gleditsia sinensis-induced antitumor effect, the sequence of events leading to cell growth inhibition in cancer cells treated with Gleditsia sinensis thorns remains unclear. The present study demonstrated that the antitumor effect of an extract of Gleditsia sinensis thorns on the p38MAPK signaling pathway involved cell cycle modulation and growth inhibition in human gastric cancer cells in vitro. Moreover, we examined MMP-9 regulation in gastric cancer SNU-5 cells following treatment with Gleditsia sinensis thorns.

\section{Materials and methods}

Materials. Polyclonal antibodies to cyclin E, CDK2 and CDK4 were obtained from Santa Cruz Biotechnology, Inc. (Santa Cruz, CA, USA). Polyclonal antibodies to cyclin D1, p21WAF1, p53, p27KIP, ERK1/2, phospho-ERK, p38 MAP kinase, phospho-p38 MAP kinase, JNK and phospho-JNK were obtained from New England Biolabs (Beverly, MA, USA). U0126 and SB203580 were obtained from Calbiochem (San Diego, CA, USA). A polyclonal antibody to MMP-9 was obtained from Chemicon (Temecula, CA, USA).

Preparation of the extract. Air-dried and crushed Gleditsia sinensis thorns (100 g) were added to ethanol, and extraction was performed by heating at $100^{\circ} \mathrm{C}$. The extract was then concentrated with a rotary evaporator and lyophilized. The final extract weighed $10 \mathrm{~g}$ (a collection rate of 10\%), and was diluted with saline solution.

Cell cultures. The human SNU-5 gastric cancer cell line was obtained from the American Type Culture Collection (Manassas, VA, USA). The cells were maintained in DMEM (4.5 g glucose/liter) supplemented with $10 \%$ fetal calf serum, L-glutamine, and antibiotics (Biological Industries, Beit Haemek, Israel) at $37^{\circ} \mathrm{C}$ in a $5 \% \mathrm{CO}_{2}$ humidified incubator.

Cell viability assay. Subconfluent, exponentially growing SNU-5 cells in 96-well plates, were incubated with the ethanol extract of Gleditsia sinensis thorns (EEGS) for various periods of time. Cell viability was determined using a modification of a 3-(4,5-dimethylthiazol-2-yl)-2,5-diphenyltetrazolium bromide (MTT) assay, which was based on the conversion of the tetrazolium salt 3-(4,5-dimethylthiazol-2-yl)5-(3-carboxymethoxyphenyl)-2-(4-sulfophenyl)-2-tetrazolium to a formazan product by mitochondrial dehydrogenase (31). The formazan product was quantified by measuring the absorbance at $490 \mathrm{~nm}$.

Apoptosis detection by ELISA. Detection of cell apoptosis was based on the quantification of the enrichment of monoand oligo-nucleosomes in the cytoplasm using a Cell Death Detection ELISA kit (Roche, Mannheim, Germany). Briefly, after treatment of cells with EEGS, the cells were lysed and centrifuged. The supernatant containing the cytoplasmic histone-associated DNA fragments was transferred to a microplate coated with streptavidin, and was then reacted with a mixture of the anti-histone antibodies labeled with biotin and anti-DNA antibodies coupled with peroxidase. Peroxidase was thereafter added as a substrate, and the development of the color was read photometrically at $405 \mathrm{~nm}$ with $490 \mathrm{~nm}$ as the background. The specific enrichment of mono- and oligo-nucleosomes released into the cytoplasm was expressed as an enrichment factor compared with the control.

Cell cycle analysis (FACS). Cells were harvested, fixed in $70 \%$ ethanol, and stored at $-20^{\circ} \mathrm{C}$. Cells then were washed twice with ice-cold PBS and incubated with RNase and a DNA intercalating dye, propidium iodide. Cell cycle phase analysis was performed using a Becton Dickinson FACStar flow cytometer equipped with Becton Dickinson Cell Fit software.

Immunoprecipitation and immunoblotting. Growth-arrested cells were treated with EEGS in the presence of $10 \%$ FBS for various time periods at $37^{\circ} \mathrm{C}$. Cell lysates were prepared, and immunoprecipitation and immunoblotting were performed as previously described $(31,36)$.

Zymography. The conditioned medium was electrophoresed in a polyacrylamide gel containing gelatin at a concentration of $1 \mathrm{mg} / \mathrm{ml}$. The gel was washed at room temperature for $2 \mathrm{~h}$ with $2.5 \%$ Triton $\mathrm{X}-100$ and then at $37^{\circ} \mathrm{C}$ overnight in a buffer containing $10 \mathrm{mM} \mathrm{CaCl}_{2}, 150 \mathrm{mM} \mathrm{NaCl}$ and $50 \mathrm{mM}$ Tris- $\mathrm{HCl}$ (pH 7.5). The gel was stained with $0.2 \%$ Coomassie blue and photographed on a light box. Proteolysis was detected as a white zone in a dark blue field.

Nuclear extracts and electrophoretic mobility shift assay. Nuclear extracts were essentially prepared as described elsewhere $(31,36)$. Cultured cells were collected by centrifugation, washed and suspended in a buffer containing $10 \mathrm{mM}$ HEPES (pH 7.9), 10 mM KCl, $0.1 \mathrm{mM}$ EDTA, $0.1 \mathrm{mM}$ EGTA, $1 \mathrm{mM}$ DTT and $0.5 \mathrm{mM}$ PMSF. After $15 \mathrm{~min}$ on ice, the cells were vortexed in the presence of $0.5 \%$ Nonidet NP-40. The nuclear pellet was then collected by centrifugation for $15 \mathrm{~min}$ at $4^{\circ} \mathrm{C}$ and extracted in a buffer containing $20 \mathrm{mM}$ HEPES (pH 7.9), $0.4 \mathrm{M} \mathrm{NaCl}, 1 \mathrm{mM}$ EDTA, $1 \mathrm{mM}$ EGTA, $1 \mathrm{mM}$ DTT and $1 \mathrm{mM}$ PMSF.

The nuclear extract $(10-20 \mu \mathrm{g})$ was preincubated at $4^{\circ} \mathrm{C}$ for 30 min with a 100 -fold excess of an unlabeled oligonucleotide spanning the -79 MMP-9 cis element of interest. The sequences were: AP-1, CTGACCCCTGAGTCAGCACTT; NF- $\mathrm{B}, \mathrm{CAG}$ TGGAATTCCCCAGCC; Sp-1, GCCCATTCCTTCCGCC CCCAGATGAAGCAG. The reaction mixture was then 
A

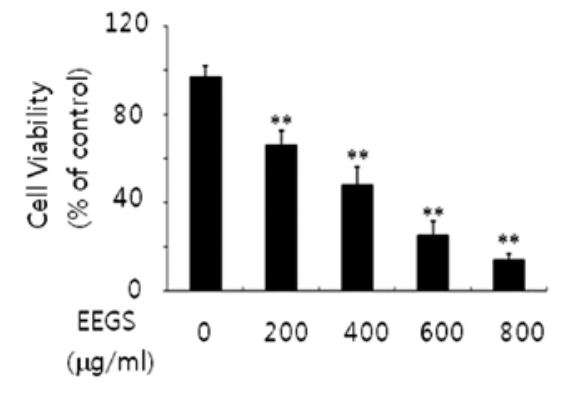

B

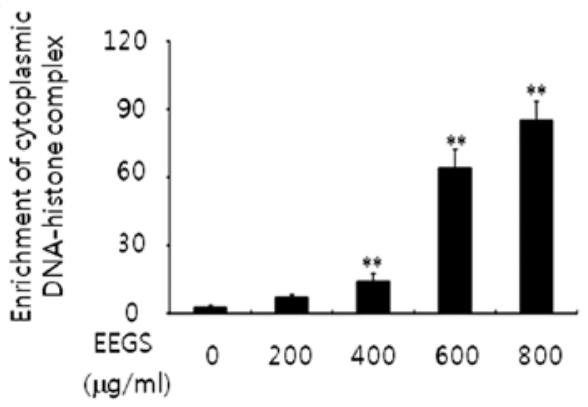

Figure 1. Induction of cell growth inhibition and apoptosis in EEGS-treated SNU-5 cells. (A) Subconfluent exponentially growing cells were treated with EEGS for $24 \mathrm{~h}$ at the indicated concentrations in 10\% DMEM. Cell viability was determined using a modification of the MTT assay. (B) Detection of apoptosis in cells treated with EEGS. The cells were treated in the absence or presence of EEGS in $10 \%$ serum medium for $24 \mathrm{~h}$. Enrichment of cytoplasmic DNA-histone complex was measured by ELISA. Results are presented as the means \pm SE from three triplicate experiments. ${ }^{* * *} \mathrm{P}<0.01$ compared with no EEGS treatment

incubated at $4^{\circ} \mathrm{C}$ for $20 \mathrm{~min}$ in a buffer $(25 \mathrm{mM}$ HEPES buffer pH 7.9, $0.5 \mathrm{mM}$ EDTA, $0.5 \mathrm{mM}$ DTT, $0.05 \mathrm{M} \mathrm{NaCl}$ and $2.5 \%$ glycerol) with $2 \mu \mathrm{g}$ of poly $\mathrm{dI} / \mathrm{dC}$ and $5 \mathrm{fmol}\left(2 \times 10^{4} \mathrm{cpm}\right)$ of a Klenow end-labeled $\left({ }^{32} \mathrm{P}-\mathrm{ATP}\right) 30$-mer oligonucleotide, spanning the DNA-binding site of the MMP-9 promoter. The reaction mixture was electrophoresed at $4^{\circ} \mathrm{C}$ in a $6 \%$ polyacrylamide gel using a TBE $(89 \mathrm{mM}$ Tris, $89 \mathrm{mM}$ boric acid and $1 \mathrm{mM}$ EDTA) running buffer. The gel was rinsed with water, dried and exposed overnight to X-ray film.

Statistical analysis. Where appropriate, data were expressed as the means \pm SE. Data were analyzed using factorial ANOVA and a Fisher's least significant differences test where appropriate. Statistical significance was set at $\mathrm{P}<0.05$.

\section{Results}

EEGS treatment reduces the proliferation of human $S N U-5$ gastric cancer cells. To assess the effect of EEGS on cell proliferation and cell death, SNU-5 cells were treated with 200, 400, 600 and $800 \mu \mathrm{g} / \mathrm{ml}$ doses of EEGS for $24 \mathrm{~h}$. Cells treated with EEGS demonstrated a concentration-dependent inhibition of cell growth (Fig. 1A). In addition, as shown in Fig. 1B, using an ELISA-based assay, we observed an increase in cytoplasmic DNA-histone complexes (>600 $\mu \mathrm{g} / \mathrm{ml})$, which is associated with apoptosis, in the EEGS-treated cells. Cells treated with the vehicle (ethanol) showed no changes in the basal levels of cell growth and cell death (data not shown). These data suggest a strong growth inhibitory effect and an apoptotic effect in EEGS-treated SNU-5 cells.
A

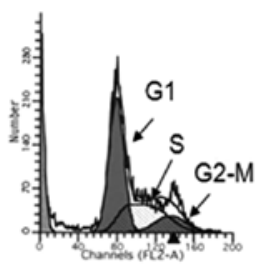

C

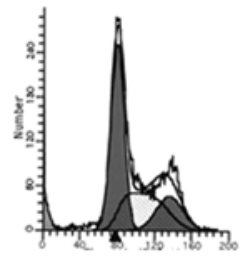

B

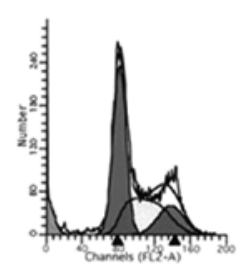

D

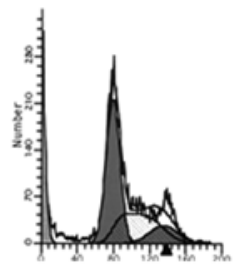

$E$

\begin{tabular}{cccc}
\hline & GO/G1 & S & G2/M \\
\hline (A) Control & 32.12 & 18.1 & 49.78 \\
(B) EEGS $(100 \mu \mathrm{g} / \mathrm{ml})$ & 43.61 & 15.95 & 40.44 \\
(C) $\operatorname{EEGS~}(200 \mu \mathrm{g} / \mathrm{ml})$ & 49.47 & 15.37 & 35.16 \\
(D) $\operatorname{EEGS~}(400 \mu \mathrm{g} / \mathrm{ml})$ & 56.02 & 14.75 & 29.23
\end{tabular}

Figure 2. Effect of EEGS treatment on the cell cycle progression in SNU-5 cells. Cells were cultured with (A) 0, (B) 100, (C) 200 and (D) $400 \mu \mathrm{g} / \mathrm{ml}$ EEGS. After $24 \mathrm{~h}$ of treatment, cells were processed to assess the change in the cell cycle distribution by flow cytometric analysis. (E) The percentage of stained cellular DNA in each population is shown as the mean \pm SE from three triplicate experiments.

EEGS treatment induces $G 1$ phase cell cycle arrest. Since EEGS treatment resulted in a strong inhibitory effect on cell growth of SNU-5 cells, we analyzed the cell cycle distribution using flow cytometry. SNU-5 cells exhibited an accumulation of the DNA content characteristic of the G1 phase cell cycle following treatment with EEGS $(400 \mu \mathrm{g} / \mathrm{ml})$, based on a comparison with the control (Fig. 2). To investigate the mechanism controlling the G1 phase of the cell cycle, we further examined the effects of EEGS treatment on the levels of cyclins and CDKs, which are associated with the G1 phase of the cell cycle. EEGS treatment for $24 \mathrm{~h}$ resulted in complete inhibition of the expression of cyclin D1 and cyclin E, as well as a decrease in CDK2 and CDK4 proteins (Fig. 3A). Cell lysates were next examined for kinase activity of CDK2 and CDK4 immunoprecipitates in the EEGS-treated cells. EEGS treatment inhibited CDK2- and CDK4-associated kinase activities in the SNU-5 cells in a dose-dependent manner (Fig. 3B).

p21WAF1 is associated with EEGS-induced G1 phase cell cycle arrest. Cyclin-dependent kinase inhibitors (CDKIs) are negative regulatory proteins that bind to $\mathrm{CDK} /$ cyclin complexes and inhibit kinase activities (11). Based on our results demonstrating the cell cycle arrest effect of EEGS, immunoblotting was performed to determine whether EEGS modulates the expression levels of CDKIs. Our results indicated that treatment of SNU-5 cells with EEGS for $24 \mathrm{~h}$ induced 


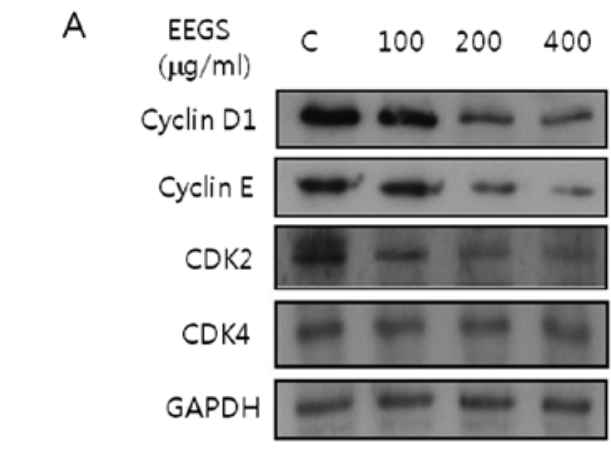

B

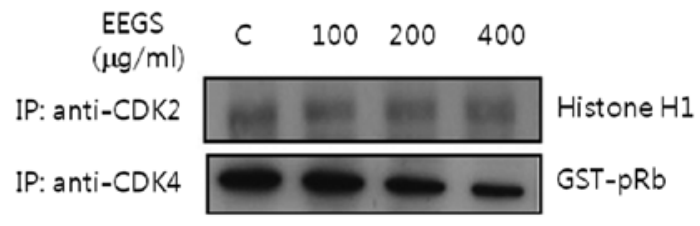

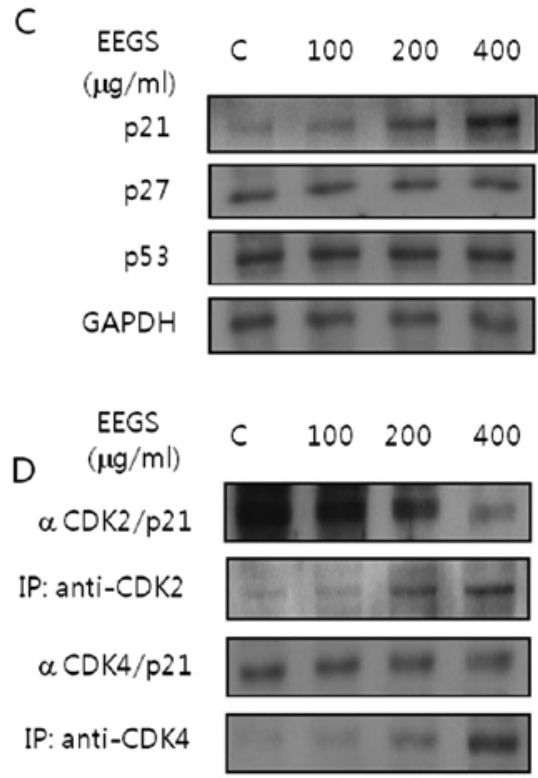

Figure 3. p21WAF1 is associated with the EEGS-induced G1 phase cell cycle arrest in SNU-5 cells. (A and C) The SNU-5 cells were treated with the indicated concentrations of EEGS for $24 \mathrm{~h}$, and immunoblot analysis was performed with antibodies specific for cyclin D1, cyclin E, CDK2, CDK4, p21WAF1, p27KIP1 and 553 . The results from representative experiments were normalized to GAPDH expression. (B) Equal amounts of cell lysates were immunoprecipitated (IP) with anti-CDK2 and anti-CDK4 antibodies. The histone H1 (for CDK2) or GST-Rb (for CDK4) proteins were used as substrates for kinase activities. (D) The cell lysates from control and EEGS-treated cells were subjected to immunoprecipitation with anti-CDK2 and anti-CDK4 antibodies. The immunoprecipitates were followed by immunoblot analysis with an anti-p21WAF1 antibody. The results from representative experiments were normalized to immunoprecipitated CDK2 and CDK4 expression.

A

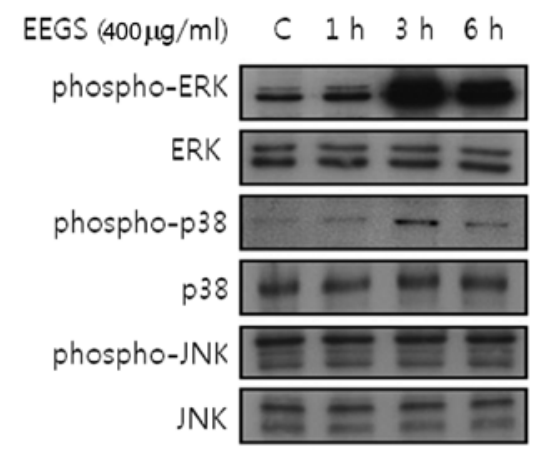

\section{B}

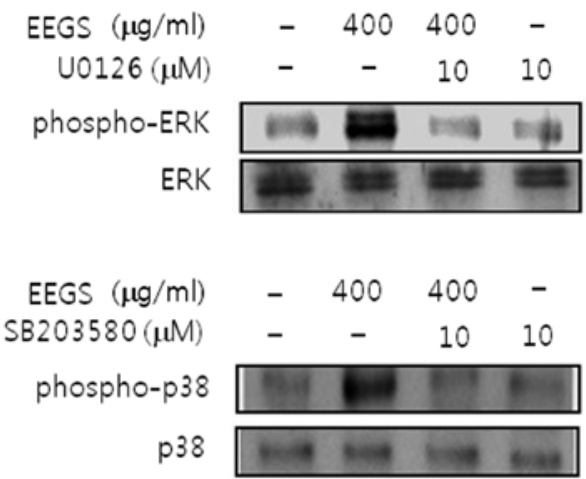

Figure 4. EEGS stimulated activation of ERK1/2 and p38 MAP kinase. (A) SNU-5 cells were treated with EEGS (400 $\mu \mathrm{g} / \mathrm{ml}$ ) for 1,3 and $6 \mathrm{~h}$. The cell lysates were harvested and lysed. Immunoblot analysis was performed with antibodies phospho-specific for ERK1/2, JNK and p38 MAP kinase. (B) The cells were pretreated for $40 \mathrm{~min}$ with $\mathrm{U} 0126(10 \mu \mathrm{M})$ and SB203580 $(10 \mu \mathrm{M})$ prior to treatment with EEGS $(400 \mu \mathrm{g} / \mathrm{ml})$ for $3 \mathrm{~h}$.

the expression levels of p21WAF1 in a dose-dependent manner compared with untreated cells (Fig. 3C). However, EEGS treatment resulted in no noticeable change in the induction of p27KIP1 and p53 tumor-suppressor proteins in the SNU-5 cells (Fig. 3C). These results clearly showed that p21WAF1 is involved in EEGS-induced G1 phase cell cycle arrest. Next, we determined the effect of EEGS on the interaction between p21WAF1 and CDKs. The cell lysates from control and EEGS-treated cells were immunoprecipitated using antiCDK2 or anti-CDK4 antibody, respectively. In addition, the immune complex was analyzed for the presence of p21WAF1 by immunoblotting. As shown in Fig. 3D, EEGS increased the association of CDK2 with p21WAF1. In addition, the interaction of p21WAF1/CDK 4 complexes was maintained at high levels in SNU-5 cells $24 \mathrm{~h}$ after EEGS treatment (Fig. 3D).
These results suggest that the increased association between p21WAF1 and CDKs plays an important role in inhibiting CDK kinase activity, accompanied by G1 phase cell cycle arrest following EEGS treatment in SNU-5 cells.

EEGS treatment activates ERK1/2 and p38 MAP kinase in $S N U-5$ cells. To examine whether MAPK signaling pathways are involved in the inhibition of cell growth induced by EEGS, immunoblotting was carried out. EEGS treatment induced activation of ERK1/2 and p38 MAP kinase (Fig. 4A). In addition, the activation of ERK1/2 and p38 MAP kinase was inhibited by the presence of specific kinase inhibitors such as U0126 (ERK1/2) and SB203580 (p38 MAP kinase), respectively (Fig. 4B). However, EEGS had no effect on JNK activation (Fig. 4A). These results suggest that EEGS treatment could be 
A

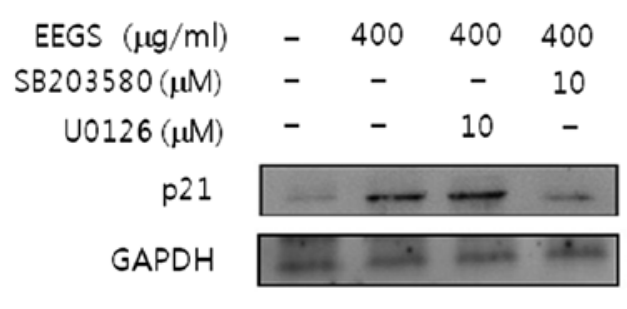

B

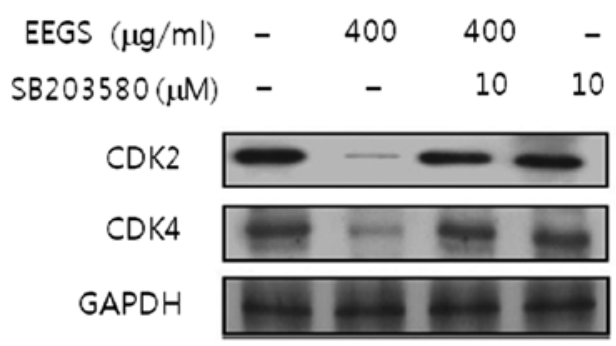

C

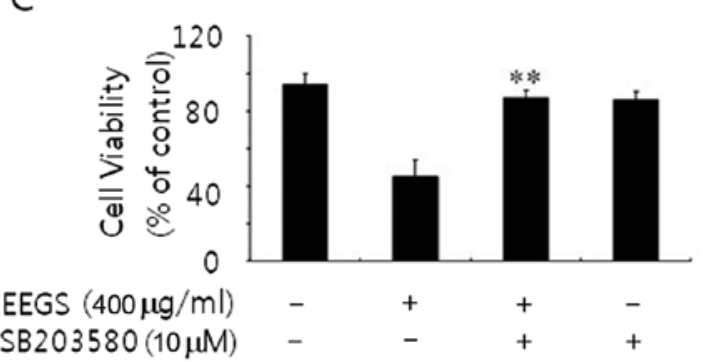

Figure 5. p38 MAP kinase participates in p21WAF1 expression, the expression of G1 phase cell cycle-associated proteins, and growth inhibition in EEGStreated SNU-5 cells. (A and B) Cells were pre-incubated for $40 \mathrm{~min}$ in the absence or presence of U0126 (10 $\mu \mathrm{M})$ or SB203580 (10 $\mu \mathrm{M}$ ), prior to treatment with $400 \mu \mathrm{g} / \mathrm{ml}$ EEGS for $24 \mathrm{~h}$. Immunoblot analysis was then performed with antibodies specific for p21WAF1, CDK2 and CDK4. The results from representative experiments were normalized to GAPDH expression. (C) Cells were pre-treated with $10 \mu \mathrm{M} \mathrm{SB} 203580$ for $40 \mathrm{~min}$ before cells were treated with $400 \mu \mathrm{g} / \mathrm{ml}$ EEGS for $24 \mathrm{~h}$. MTT assays were carried out as detailed in Materials and methods. Indicated values are the means of triplicate wells. ${ }^{* *} \mathrm{P}<0.01 \mathrm{compared}$ with EEGS treatment.

used to activate the ERK1/2 and p38 MAP kinase signaling pathways in SNU-5 cells.

SB203580, a specific inhibitor of p38 MAP kinase, reverses increased p21WAF1 expression and decreased CDK levels in EEGS-treated SNU-5 cells. To confirm whether MAPK is associated with EEGS-induced G1 phase cell cycle arrest, we next examined the p21WAF1 expression and CDK levels using immunoblotting following pretreatment with MAP kinase-specific kinase inhibitors. As shown in Fig. 5A, the p21WAF1 expression induced by EEGS was inhibited in the presence of SB203580. However, U0126 treatment had no effect on EEGS-induced p21WAF1 expression (Fig. 5A). In addition, the decreased expression of CDK2 and CDK4 at the protein levels was also reversed by pretreatment with SB203580 (Fig. 5B). These results indicate that the p38 MAP kinase signaling pathway is involved in G1 phase cell cycle arrest via expression of p21WAF1.

Inhibition of ERK recovers the inhibitory growth effects in EEGS-treated SNU-5 cells. To further investigate the potential role of p38 MAP kinase on the EEGS-induced inhibition of cell growth, an MTT assay was performed following pretreatment with SB203580. To accomplish this experiment, SNU-5 cells were untreated or treated with EEGS in the absence or presence, respectively, of SB203580. Incubation of cells with SB203580 blocked the decrease in cell growth in EEGS-treated SNU-5 cells (Fig. 5C), as compared with that in cells treated with EEGS alone. Our results suggest that the p38 MAP kinase signaling pathway in SNU-5 cells is associated with the cell growth inhibition that is induced by EEGS.
EEGS abolishes TNF- $\alpha$-induced MMP-9 expression via a reduction in $N F-\kappa B$ and $A P-1$ binding activity. To determine the effect of EEGS on MMP-9 expression in TNF- $\alpha$-treated SNU-5 cells, gelatin zymography assay was performed. The results showed an increase in MMP-9 expression following treatment with TNF- $\alpha$ (Fig. 6A). TNF- $\alpha$-induced MMP-9 secretion was inhibited by pre-incubation of SNU-5 cells with EEGS (Fig. 6A). By contrast, there was no effect on constitutive MMP-2 expression in the presence of either TNF- $\alpha$ or EEGS (Fig. 6A). Similar results were observed in the immunoblot analysis (Fig. 6A). Next, gel-shift assays were performed to identify the potential transcription factors by which TNF- $\alpha$ regulates MMP-9 expression. As shown in Fig. 6B, TNF- $\alpha$ increased the binding for both NF- $\mathrm{B}$ and AP-1 motifs in the SNU-5 cells. However, $\mathrm{Sp}-1$ binding activity was not stimulated in response to TNF- $\alpha$ (Fig. 6B). Finally, we investigated the possible implications of transcription factors NF- $\kappa$ B and AP-1 in the regulation of MMP-9 in response to TNF- $\alpha$ by EEGS. As shown in Fig. 6B, both NF- $\kappa \mathrm{B}$ and AP-1 DNA binding activities were almost abolished by pretreatment with EEGS in TNF- $\alpha$-treated SNU-5 cells. These results suggest that EEGS inhibited TNF- $\alpha$-induced MMP-9 expression via a decrease in the activation of NF- $\kappa$ B and AP-1 motifs in SNU-5 cells.

\section{Discussion}

Many types of antitumor agents have been effective against tumor initiation and the promotion of tumorigenesis (3-5). However, crucial problems, such as side-effects and the occurrence of drug resistance, must be overcome for the effective treatment of gastric cancer $(6,7,30)$. Recently, use of the biological properties of natural plants to develop antitumor 

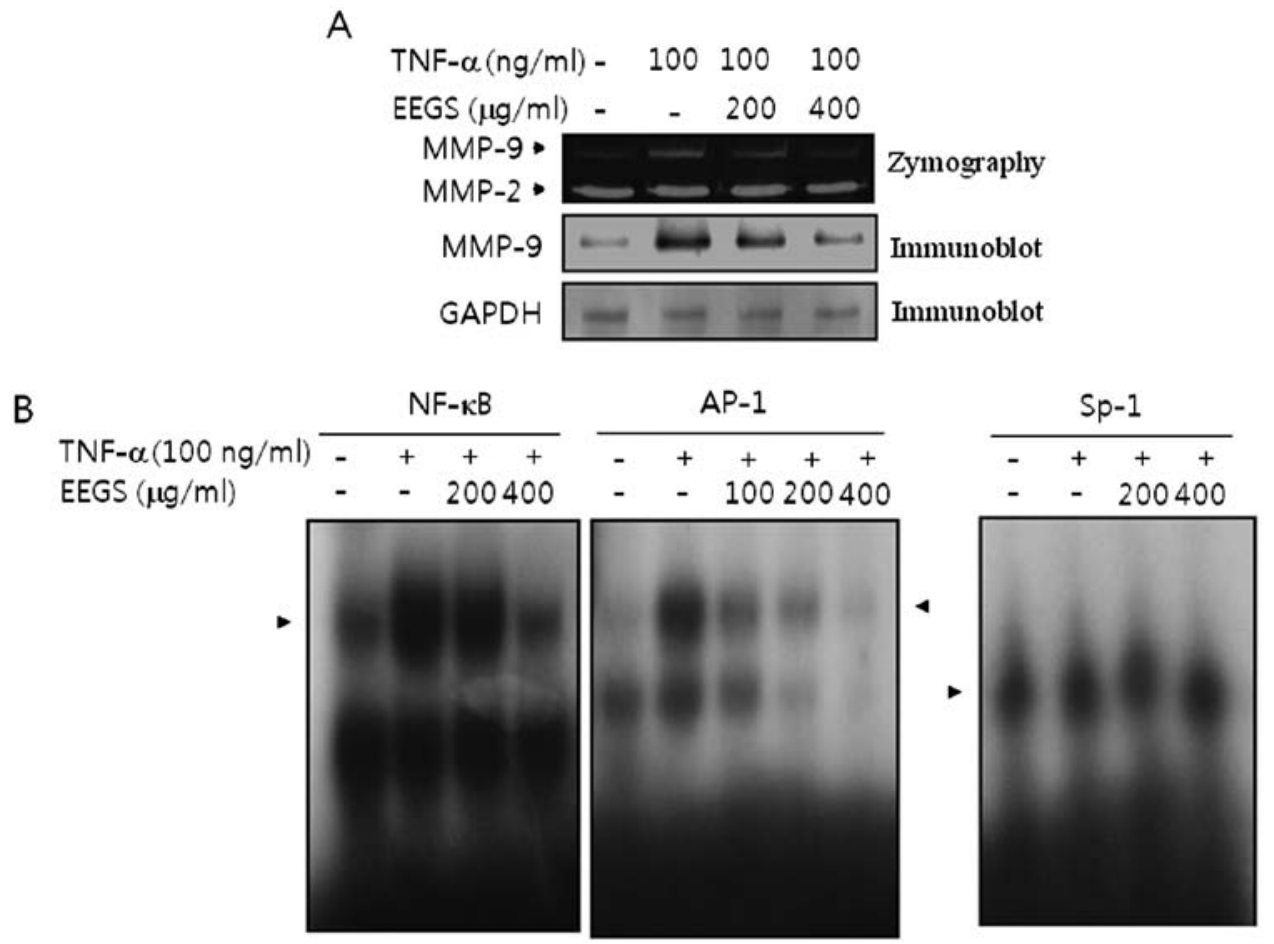

Figure 6. EEGS suppresses TNF- $\alpha$-stimulated MMP-9 expression via decreased DNA-binding activity of NF-kB and AP-1 in SNU-5 cells. After a one-day culture in serum-free medium, cells were pretreated for $40 \mathrm{~min}$ with EEGS at the indicated concentrations ( $200 \mathrm{or} 400 \mu \mathrm{g} / \mathrm{ml})$, followed by stimulation with or without TNF- $\alpha(100 \mathrm{ng} / \mathrm{ml})$ for $24 \mathrm{~h}$. (A) The culture supernatants were collected and analyzed zymographically for MMP activity. Similarly, cell lysates were subjected to immunoblot analysis with antibodies specific for MMP-9 and GAPDH. (B) After incubation, nuclear extracts were isolated and then analyzed for binding activities of NF-kB, Sp-1, or AP-1 using EMSA with radiolabeled oligonucleotide probes as described in Materials and methods.

agents has attracted increased interest. In the present study, we evaluated the mechanisms of an ethanol extract of Gleditsia sinensis thorns (EEGS) in the potential therapeutic effects underlying cell cycle control, signal transduction pathways and MMP regulation.

Treatment of SNU-5 cells with EEGS $(200-800 \mu \mathrm{g} / \mathrm{ml})$ resulted in inhibition of cell growth. Apoptotic cells were observed following high-dose treatments $(600-800 \mu \mathrm{g} / \mathrm{ml})$. The potential of chemopreventive or chemotherapeutic agents to suppress the growth of cancer cells is associated with blocking the $\mathrm{G} 1$ to $\mathrm{S}$ transition checkpoint. In general, G1 to $\mathrm{S}$ cell cycle progression is regulated by activation of $\mathrm{CDK}$ regulatory proteins and cyclin complexs (8-10). Therefore, the induction of G1 phase cell cycle arrest in cancer cells is proposed as a critical therapeutic approach, which inhibits cell cycle progression and tumor growth. EEGS treatment induced G1 phase cell cycle arrest, with a concomitant decrease in cyclin D1/CDK4, and cyclin E/CDK2 complexes in SNU-5 cells. These results are inconsistent with those of previous studies indicating that EEGS induced G2/M phase cell cycle arrest in colon cancer cells (31). The results of the present study demonstrated that EEGS caused G1 phase cell cycle arrest via a reduction in cyclins and CDKs, which are regulatory molecules involved in G1 to $\mathrm{S}$ cell cycle progression in SNU-5 cells.

p21WAF1, one of the CDKI family proteins (CDK inhibitors), is a universal inhibitor of CDKs, the expression levels of which are normally regulated by the kinase activity of CDK/cyclin complexes through either a p53-dependent or a p53-independent mechanism $(11,32)$. In addition, p21WAF1 plays an essential role in the cellular stress induced by anti- proliferative signals, which inhibit the G1 to $\mathrm{S}$ phase cell cycle progression (11). Previous studies have shown that accumulation of p27KIP1 is associated with G2/M phase cell cycle arrest in colon cancer cells (31). Our data revealed that EEGS increases p21WAF1 protein expression during G1 phase cell cycle arrest in SNU-5 cells. However, the expression levels of other CDKIs, including p27KIP1 and p53, remained essentially unchanged. These results suggest that induction of p21WAF1 may also be responsible for G1 phase arrest in EEGS-treated SNU-5 cells. Collectively, the mechanistic investigation showed that EEGS causes p21WAF1-mediated G1 phase cell cycle arrest via downregulation of cyclin/CDK complexes in SNU-5 cells.

Regulation of cell growth inhibition occurs through various mechanisms including the MAPK signaling pathway (12-14). In the present study, we examined the potential involvement of MAPK pathways, such as ERK, p38 MAP kinase and JNK, in the EEGS-induced inhibition of cell growth. Treatment of cells with EEGS induced activation of ERK1/2 and p38 MAP kinase. Previous studies have demonstrated that the MAPK pathway is accompanied by change in the cell cycle regulation $(13,14,33,34)$. Since EEGS induced p21WAF1 expression, the involvement of MAPK signaling pathways in EEGSinduced p21WAF1 expression was investigated. Inhibition of p38 MAP kinase, using a pharmacological inhibitor (SB203580), reversed p21WAF1 expression induced by EEGS. However, pretreatment of cells with U0126 (an ERK1/2 inhibitor) did not affect the EEGS-mediated p21WAF1 expression. These data suggest that ERK1/2 activation is not required for p21WAF1 expression in response to EEGS, although EEGS 
induces activation of ERK1/2. The results of the present study showed that the activation of p38 MAP kinase is a main factor in the regulation of EEGS-induced p21WAF1 expression in SNU-5 cells. In addition, the inhibition of p38 MAP kinase by pre-incubation with SB203580 restored the cell growth inhibition and downregulation of G1 phase cell cycle-associated proteins, CDK2 and CDK4. Our findings obtained by the inhibition of p38 MAP kinase indicate that p38 MAP kinase is involved in the inhibition of cell proliferation by suppressing cell cycle regulatory proteins, the CDKs. The present study is the first to show that the p38 MAP kinase signaling pathway may be responsible for p21WAF1-mediated G1 phase cell cycle arrest in the EEGS-mediated inhibition of cell growth.

Matrix metalloproteinase-9 (MMP-9) is a major component involved in the degradation of the extracellular matrix (ECM) and participates in the metastatic progression of gastric cancer (17-19). A previous report showed that TNF- $\alpha$ enhances MMP-9 expression in gastric cancer cell lines (35). Based on these studies, we further investigated the effects of EEGS on the regulatory mechanism of MMP-9 in TNF- $\alpha$-treated SNU-5 cells. In TNF- $\alpha$-treated cells, using both zymographic and immunoblot analyses, TNF- $\alpha$-induced MMP-9 expression was inhibited by treatment with EEGS at the protein level, without altering the level of MMP-2. It is well known that transcription factors NF- $\kappa \mathrm{B}, \mathrm{AP}-1$, and Sp-1 are involved in MMP-9 expression in response to TNF- $\alpha$ in several cell lines $(20-23,36)$. However, the identification of cis-elements in the induction of MMP-9 by TNF- $\alpha$ in gastric cancer has not been addressed to date. Our data from the present study represent the first evidence that TNF- $\alpha$ effectively enhances MMP-9 expression via increasing both AP-1 and NF- $\kappa$ B binding activities in a gastric cancer cell line. However, unexpectedly, we did not observe the $\mathrm{Sp}-1$ binding activity in TNF- $\alpha$-treated cells. In addition, we found that treatment of cells with EEGS showed significantly decreased binding activities in both AP-1 and $N F-\kappa B$ motifs in response to TNF- $\alpha$. Our results suggest that NF- $\kappa \mathrm{B}$ and AP-1 sites are important for the inhibition of EEGS-mediated MMP-9 expression in TNF- $\alpha$-treated SNU-5 cells.

In conclusion, the results of the present study revealed that EEGS-induced inhibition of cell growth was associated with p38 MAP kinase activation via p21WAF1-mediated G1 phase cell cycle arrest, which involved a decrease in the cyclin and CDK complexes in gastric cancer SNU-5 cells. In addition, EEGS significantly inhibited MMP-9 expression via the suppression of the binding activities of NF- $\kappa \mathrm{B}$ and AP-1 cis-elements in TNF- $\alpha$-treated cells. The results of the present study warrant the development of EEGS as a novel anticancer agent for the effective therapy of human gastric cancer. However, further study is required to elucidate the effects of the EEGS compound in regards to its molecular mechanisms, which are responsible for its in vivo efficacy.

\section{Acknowledgements}

This study was supported by the National Research Foundation of Korea (NRF) grant funded by the Korean government (MEST) (no. 2012-0000482) and by a grant from the NextGeneration BioGreen 21 Program (no. PJ0081952011), Rural Development Administration, Republic of Korea.

\section{References}

1. Jemal A, Siegel R, Ward E, Hao Y, Xu J and Thun MJ: Cancer statistics. CA Cancer J Clin 59: 225-249, 2009.

2. Lau M, Le A and El-Serag HB: Non-cardia gastric adenocarcinoma remains an important and deadly cancer in the United States: secular trends in incidence and survival. Am J Gastroenterol 101: 2485-2492, 2006.

3. Cervantes A, Roselló S, Roda D and Rodríguez-Braun E: The treatment of advanced gastric cancer: current strategies and future perspectives. Ann Oncol 19: 103-107, 2008.

4. Tham CK, Choo SP, Poon DYH, et al: Capecitabine with radiation is an effective adjuvant therapy in gastric cancers. World J Gastroenterol 16: 3709-3715, 2010.

5. Watanabe T, Kume K, Taip M, et al: Gastric mucosal cancer smaller than $7 \mathrm{~mm}$ can be treated with conventional endoscopic mucosal resection as effectively as with endoscopic submucosal dissection. Hepatogastroenterology 57: 668-673, 2010.

6. Kang HC, Kim IJ, Park HW, et al: Regulation of MDK expression in human cancer cells modulates sensitivities to various anticancer drugs: MDK overexpression confers to a multi-drug resistance. Cancer Lett 247: 40-47, 2007.

7. Yin F, Shi YQ, Zhao WP, Xiao B, Miao JY and Fan DM: Suppression of P-gp induced multiple drug resistance in a drug resistant gastric cancer cell line by over-expression of Fas. World J Gastroenterol 6: 664-670, 2000.

8. Sherr CJ: Cancer cell cycles. Science 274: 1672-1677, 1996.

9. Jacks T and Weinberg RA: Cell-cycle control and its watchman. Nature 381: 643-644, 1996.

10. Collins K, Jacks T and Pavletich NP: The cell cycle and cancer. Proc Natl Acad Sci USA 94: 2776-2778, 1997.

11. Peter M and Herskowitz I: Joining the complex: cyclin-dependent kinase inhibitory proteins and the cell cycle. Cell 79: 181-184, 1994.

12. Xia Z, Dickens M, Raingeaud J, Davis RJ and Greenberg ME: Opposing effects of ERK and JNK-p38 MAP kinases on apoptosis. Science 270: 1326-1331, 1995.

13. Thornton TM and Rincon M: Non-classical p38 map kinase functions: cell cycle checkpoints and survival. Int J Biol Sci 5: 44-51, 2009.

14. Han J and Sun P: The pathways to tumor suppression via route p38. Trends Biochem Sci 32: 364-371, 2007.

15. Liotta LA: Tumor invasion and metastasis-role of extracellular matrix: Rhoads Memorial Award Lecture. Cancer Res 46: 1-7, 1986.

16. Matrisian LM: Metalloproteinases and their inhibitors in matrix remodeling. Trends Genet 6: 121-125, 1990.

17. Sampieri CL, de la Peña S, Ochoa-Lara M, Zenteno-Cuevas R and León-Córdoba K: Expression of matrix metalloproteinases 2 and 9 in human gastric cancer and superficial gastritis. World $\mathbf{J}$ Gastroenterol 16: 1500-1505, 2010.

18. Zheng H, Takahashi H, Murai Y, et al: Expressions of MMP-2, MMP-9 and VEGF are closely linked to growth, invasion, metastasis and angiogenesis of gastric carcinoma. Anticancer Res 26: 3579-3583, 2006.

19. Yamanaka N, Morisaki T, Nakashima H, et al: Interleukin 1beta enhances invasive ability of gastric carcinoma through nuclear factor-kappaB activation. Clin Cancer Res 10: 1853-1859, 2004.

20. Bond M, Rosalind P, Fabunmi P, Baker AH and Newby AC: Synergistic upregulation of metalloproteinase- 9 by growth factors and inflammatory cytokines: an absolute requirement for transcription factor NF-kappa B. FEBS Lett 435: 29-34, 1998.

21. Sato H, Kita M and Seiki M: v-Src activates the expression of 92-kDa type IV collagenase gene through the AP-1 site and the GT box homologous to retinoblastoma control elements. A mechanism regulating gene expression independent of that by inflammatory cytokines. J Biol Chem 268: 23460-23468, 1993.

22. Sato $\mathrm{H}$ and Seiki M: Regulatory mechanism of $92 \mathrm{kDa}$ type IV collagenase gene expression which is associated with invasiveness of tumor cells. Oncogene 8: 395-405, 1993.

23. Farina AR, Tacconelli A, Vacca A, Maroder M, Gulino A and Mackay AR: Transcriptional up-regulation of matrix metalloproteinase-9 expression during spontaneous epithelial to neuroblast phenotype conversion by SK-N-SH neuroblastoma cells, involved in enhanced invasivity, depends upon GT-box and nuclear factor kappaB elements. Cell Growth Differ 10: 353-367, 1999.

24. Ahn DK: Illustrated Book of Korean Medicinal Herbs. Kyohak Publishing Co., Seoul, p628, 2003 
25. Lim JC, Park JH, Budesinsky M, et al: Antimutagenic constituents from the thorns of Gleditsia sinensis. Chem Pharm Bull 53: 561-564, 2005.

26. Zhou L, Li D, Wang J, Liu Y and Wu J: Antibacterial phenolic compounds from the spines of Gleditsia sinensis Lam. Nat Prod Res 21: 283-291, 2007.

27. Li WH, Zhang XM, Tian RR, Zheng YT, Zhao WM and Qiu MH: A new anti-HIV lupane acid from Gleditsia sinensis Lam. J Asian Nat Prod Res 9: 551-555, 2007.

28. Shin TY and Kim DK: Inhibitory effect of mast cell-dependent anaphylaxis by Gleditsia sinensis. Arch Pharm Res 23: 401-406, 2000.

29. Park E and Shin MJ: Anti-inflammatory activity of aqueous extract from Gleditsiae Spina. Arch Pharm Res 37: 124-128, 1993.

30. Panchal RG: Novel therapeutic strategies to selectively kill cancer cells. Biochem Pharmacol 55: 247-252, 1998.

31. Lee SJ, Cho YH, Kim H, et al: Inhibitory effects of the ethanol extract of Gleditsia sinensis thorns on human colon cancer HCT116 cells in vitro and in vivo. Oncol Rep 22: 1505-1512, 2009.
32. Macleod KF, Sherry N, Hannon G, et al: p53-dependent and independent expression of p21 during cell growth, differentiation, and DNA damage. Genes Dev 9: 935-944, 1995.

33. Chambard JC, Lefloch R, Pouyssegur J and Lenormand P: ERK implication in cell cycle regulation. Biochim Biophys Acta 1773: 1299-1310, 2007.

34. Malumbres M, Pérez De Castro I, Hernández MI, Jiménez M, Corral T and Pellicer A: Cellular response to oncogenic ras involves induction of the Cdk4 and Cdk6 inhibitor p15(INK4b). Mol Cell Biol 20: 2915-2925, 2000.

35. Kim S, Choi MG, Lee HS, et al: Silibinin suppresses TNF-alpha-induced MMP-9 expression in gastric cancer cells through inhibition of the MAPK pathway. Molecules 14: 4300$4311,2009$.

36. Moon SK, Cha BY and Kim CH: ERK1/2 mediates TNF-alphainduced matrix metalloproteinase- 9 expression in human vascular smooth muscle cells via the regulation of NF-kappaB and AP-1: involvement of the ras dependent pathway. J Cell Physiol 198: 417-427, 2004. 